\title{
DISTRIBUIÇÃO E IDENTIFICAÇÃO DE Phakopsora pachyrhizi, AGENTE CAUSAL DA FERRUGEM DA SOJA NO ESTADO DE MINAS GERAIS ${ }^{1}$
}

\author{
Identification and distribution of Phakopsora pachyrhizi causal agente of the Asian \\ rust in the Minas Gerais State
}

\author{
Patrícia Ferreira Cunha Sousa ${ }^{2}$, Eduardo Alves ${ }^{3}$, Hilário Antônio de Castro ${ }^{3}$, Paulo Estevão de Souza \\ Álvaro Manuel Rodrigues de Almeida ${ }^{4}$, Silvana Regina Hochenbach ${ }^{4}$
}

\begin{abstract}
RESUMO
A ferrugem da soja é causada por duas espécies: Phakopsora pachyrhizi e P. meibomiae. No Brasil, a doença tem sido responsável por grandes perdas dessa leguminosa nas últimas safras. Um levantamento na distribuição do patógeno e a identificação correta da espécie prevalecente nas regiões produtoras no Brasil, tornou-se necessário para orientar o planejamento das medidas de controle. A caracterização molecular baseada em PCR tem se mostrado uma ferramenta útil para atender a essa necessidade. Neste estudo, foi realizada a coleta de 86 amostras de folhas infectadas com urediniósporos de Phakopsora, nas principais regiões produtoras de soja do Estado de Minas Gerais (Triângulo, Alto Paranaíba, Noroeste, Sudoeste e Sul), envolvendo 22 municípios. A extração de DNA foi feita pelo método de CTAB. Para a reação da polimerase em cadeia (PCR) foram utilizados conjuntos de "primers" específicos para cada espécie Phakopsora, sendo o par de "primers" Ppm1/Ppa2 específico para P. pachyrhizi e Ppm1/ Pme2 para $P$. meibomiae. Os resultados evidenciam que todas as 86 amostras analisadas pertenciam à espécie $P$. pachyrhizi, agente etiológico da ferrugem "asiática", ou seja, houve o aparecimento de bandas específicas apenas com o uso do conjunto "primer" Ppm1/ Ppa2 com tamanho aproximado de 141 pares de bases. De acordo com esses resultados, pode-se afirmar que a espécie do gênero Phakopsora presente em 100\% das áreas analisadas no Estado de Minas Gerais era P. pachyrhizi. Essas informações são importantes para orientar futuros programas de melhoramento, visando resistência ao agente da ferrugem da soja no Estado.
\end{abstract}

Termos para indexação: PCR, Phakopsora pachyrhizi, levantamento.

\section{ABSTRACT}

The soybean rust is caused by two species: Phakopsora pachyrhizi e P. meibomiae. In Brazil this diseases has been responsible for great losses in the production of soybean in the last years. The distribution of the disease and identification of the prevalent species in the producing areas in Brazil became necessary to guide the planning control measures. The molecular characterization based on PCR has been showing as useful tool to satisfy that need. In this study 86 samples of leaves infected by Phakopsora from the main areas producing soybean in the State of Minas Gerais (Triângulo, Alto Paranaíba, Noroeste, Sudoeste and Sul) were used. The extraction of DNA was made by the method of CTAB. For the polimerase chain reaction, specific primers were used for each species, been primer Ppm1/Ppa2 specific for $P$. pachyrhizi and Ppm1/Pme2 specific for $P$. meibomiae. The results showed that the 86 samples belonged to the species $P$. pachyrhizi, agent causal of the "Asian" rust. In other words, there was the production of bands specific from the group primer Ppm1/Ppa2 with approximate size of 141 pairs of bases. These results show that the species Phakopsora present in $100 \%$ of the areas analyzed in the State of Minas Gerais was P. pachyrhizi. This information is important to guide futures breeding programs for resistance to the agent of soybean rust in the State.

Index terms: PCR, Phakopsora pachyrhizi, survey.

\section{(Recebido em 22 de junho de 2005 e aprovado em 8 de maio de 2006)}

\section{INTRODUÇÃOO}

A ferrugem da soja, nas últimas safras, principalmente na de 2003/04, causou enormes perdas à sojicultura nacional, gerando uma redução de 4,6 milhões de toneladas, o que corresponde ao valor de US\$ 1.22 bilhão de doláres de prejuízo (YORINORI \& LAZZAROTTO, 2004). Essa doença é causada por duas espécies Phakopsora pachyrhizi (Sydow \& P. Sydow) e Phakopsora meibomiae (Arthur) Arthur. A primeira, conhecida no oriente desde 1914 (RYTTER et al., 1984) é a mais agressiva, causando perdas de $5 \%$ a $80 \%$ (KAWUKI et al., 2003); a segunda originária do hemisfério ocidental, principalmente América do Sul e Caribe, é menos agressiva. Como as duas espécies podem ocorrer simultaneamente na mesma área, com sintomatologia semelhante, porém causando perdas distintas, é de extrema importância diferenciar a espécie predominante. Na safra 2002/03, Piuga et al. (2004) realizaram levantamento em diferentes regiões do Brasil, constatando a presença simultânea das duas

Parte da dissertação de mestrado da primeira autora - DFP/UFLA.

${ }^{2}$ Bolsista CNPq - Av. Antônio Inácio de Araújo, 466 - Apto 4 - Jardim Nova Aparecida - 16883-380 - Jaboticabal, SP - patriciamaranhao@ig.com.br ${ }^{3}$ Departamento de Fitopatologia/DFP, Universidade Federal de Lavras/UFLA - Cx. P. 3037 - 37200-000 - Lavras, MG - ealves@ufla.br; proad@ufla.br; pauleste@ufla.br

${ }^{4}$ Empresa Brasileira de Pesquisa Agropecuária - Embrapa Soja/Centro Nacional de Pesquisa de Soja - Cx. Postal 231, CEP 86001-970, Londrina, PR amra@cnpso.embrapa.br; silvana@cnpso.embrapa.br 
espécies em amostras das regiões de Passo Fundo (RS) e Ponta Grossa (PR). Em Minas Gerais, a doença ocorreu na safra 2003/04 desde os primeiros estádios vegetativos da cultura, em meados de dezembro. No Estado, existe a dúvida de qual espécie está dominando os campos de produção de soja, além do que a diagnose de campo dessa doença é também dificultada, pois os sintomas iniciais podem ser confundidos com sintomas de outras doenças, como pústula bacteriana (Xanthomonas axonopodis pv. glycines (Nakano) Dye.) e mancha parda (Septoria glycines Hemmi) (YORINORI, 2003), fazendo com que um diagnóstico rápido e preciso se torne necessário.

Técnicas moleculares têm se mostrado bastante eficientes para atender a essas necessidades. Com o uso dessas técnicas, tornou-se possível a distinção entre espécies morfológica e geneticamente semelhantes (MCDONALD, 1997). Dentre as técnicas, a PCR se destaca devido à sua especificidade, a qual tem evoluido muito nos últimos anos com o desenvolvimento de "primers" para rotina (SCHAAD \& FREDERICK, 2002). No caso da ferrugem da soja, o desenvolvimento de "primers" específicos para as espécies $P$. meibomiae e $P$. pachyrhizi (FREDERICK et al., 2002) permitiu a identificação precisa de cada espécie.

Este trabalho teve como objetivo identificar, através de análise de PCR a presença e a distribuição de $P$. pachyrhizi e $P$. meibomiae nos campos de produção de soja no Estado de Minas Gerais.

\section{MATERIAL E MÉTODOS}

Amostras de folhas com lesões típicas de ferrugem foram coletadas nas principais regiões produtoras de soja do Estado de Minas Gerais, compreendendo as macrorregiões sul, sudeste, sudoeste, triângulo, alto Paranaíba e noroeste (Tabela 1), num total de 22 municípios. As amostras de folhas coletadas foram levadas para o Laboratório de Microscopia Eletrônica (LME) da Universidade Federal de Lavras, onde os urediniósporos foram retirados com um pincel $n^{\circ} 6$ e colocados em tubos de microcentrífuga de $1,5 \mathrm{~mL}$, com água destilada e esterilizada, e conservados em nitrogênio líquido a $-196^{\circ} \mathrm{C}$ e no freezer a $-20^{\circ} \mathrm{C}$.

No Laboratório de Biotecnologia da Embrapa Soja, em Londrina, PR, aproximadamente $10 \mathrm{mg}$ de urediniósporos foram colocados em tubos de microcentrífuga de 1,5 mL. Foram adicionados, em cada tubo, $500 \mu \mathrm{L}$ de tampão de extração CTAB $(\mathrm{NaCl} 5 \mathrm{M}$, Tris$\mathrm{HCl} \mathrm{M} \mathrm{pH} 8,0$, EDTA 0,5M, $\beta$-mercaptoetanol, CTAB 5\%, água destilada). Os esporos foram macerados com pistilo e incubados a $65^{\circ} \mathrm{C}$, por 60 minutos, e, posteriormente, resfriados e centrifugados por 10 minutos a $2940 \mathrm{~g}$. Em seguida, o sobrenadante foi resgatado para novo tubo, onde foi adicionado volume igual de clorofórmio: álcool isoamílico (24:1), com agitação suave por inversões, durante cinco minutos, e centrifugação por 15 minutos a $2940 \mathrm{~g}$; os dois últimos passos foram repetidos. O sobrenadante foi transferido para novo microtubo e o DNA foi precipitado pela adição de $2 / 3$ de isopropanol gelado $\left(-20^{\circ} \mathrm{C}\right)$. Os microtubos foram agitados manualmente até que os ácidos nucléicos se tornassem visíveis e depois incubados até o dia seguinte a $4^{\circ} \mathrm{C}$, quando foi centrifugado a $6610 \mathrm{~g}$, por 10 minutos. A seguir, o sobrenadante foi descartado e o "pellet" de DNA lavado com $500 \mu \mathrm{L}$ de etanol $70 \%$, seco em estufa a $37^{\circ} \mathrm{C}$, ressuspendido em $400 \mathrm{~mL}$ de tampão TE $(10 \mathrm{~mL}$ Tris-HCl pH 8,0; $1 \mathrm{~mL}$ EDTA pH 8,0) mais RNAse $(40$ $\mu \mathrm{L} / \mathrm{mg}$ ) e incubado em estufa a $37^{\circ} \mathrm{C}$ por 30 minutos. $\mathrm{O}$ DNA foi quantificado e qualificado utilizando amplificações por PCR.

Os "primers" específicos Ppm1/Ppa2 (5'GCAGAAT TCAGTGAA TCATCAAG-3'/5' GCAACACTCAAAATCCAACAAT-3’) para $P$. pachyrhizi e Ppm1/Pme2 (5'-GCAGAATTCAGTGAATCATCAAG-3'/ 5'-GCACTCAAA-ATCCAACATGC-3') para $P$. meibomiae foram sintetizados pela Invitrogen Life Thecnologies ${ }^{\circledR}$, segundo padrões desenhados por Frederick et al. (2002). As reações de PCR foram conduzidas em termociclador (Gene AMP PCR System 9700; Applied Biosystems ${ }^{\circledR}$ ) com $30 \mathrm{ng}$ de DNA genômico. A reação de PCR foi realizada seguindo o protocolo de Frederick et al. (2002), com algumas modificações nos tempos e nos números de ciclos, devido aos pré-testes, seguindo o protocolo inicial, não terem dado bons resultados. Desse modo, um volume total de $25 \mu \mathrm{L}$ contendo $100 \mathrm{mM}$ Tris- $\mathrm{HCl} ; 500 \mathrm{mM} \mathrm{KCl}, \mathrm{pH} 8.3 ; 50 \mathrm{mM}$ $\mathrm{MgCl}_{2}$; dATP, dGTP, dCTP, dTTP cada um na concentração de 2,5 mM; cada "primer" na concentração de $10 \mu \mathrm{M}$; e $1 \mathrm{U}$ $(0,2 \mu \mathrm{L})$ da Taq DNA polimerase. A desnaturação foi realizada a $94^{\circ} \mathrm{C}$, por três minutos; para amplificação foram realizados 30 ciclos $94^{\circ} \mathrm{C}$, por um minuto, $55^{\circ} \mathrm{C}$ por um minuto, $72^{\circ} \mathrm{C}$ por um minuto e 30 segundos, e para anelamento e extensão da fita foi feito sob $72^{\circ} \mathrm{C}$, por sete minutos.

Como controle negativo foi utilizada amostra sem DNA e como controles positivos amostras com DNA de $P$. pachyrhizi e $P$. meibomiae fornecidos pelo Laboratório de Biotecnologia da Embrapa Soja. As amostras foram submetidas à eletroforese em cuba horizontal, por três horas a $120 \mathrm{~V}$. O gel a $1,5 \%$ de agarose foi corado com brometo de etídio e revelado em luz ultra-violeta. 
TABELA 1 - Relação das amostras de urediniósporos de ferrugem coletados nas principais regiões produtoras de soja no Estado de Minas Gerais. Lavras, MG, 2005.

\begin{tabular}{|c|c|c|}
\hline $\mathbf{N}^{\mathbf{0}}$ & Cidade & Cultivar \\
\hline 1 a 3 & Casa-de-vegetação DFP/UFLA & BRS-215 \\
\hline 4 e 6 & Lavras & Embrapa-48 \\
\hline 5 & Lavras & Pintado \\
\hline 7 & Lavras & M-SOY 109 \\
\hline 8 a 11 & Nova Ponte & Garantia \\
\hline 12 a 15 & Santa Juliana & Nobreza \\
\hline 16 & Capitólio & M-SOY 8001 \\
\hline 17 & Capitólio & Conquista \\
\hline 18 a 32 & Delfinópolis & Conquista \\
\hline 33 a 36 & Passos & Conquista \\
\hline 37 & São Gotardo & Vencedora \\
\hline 38 & Patos de Minas & Conquista \\
\hline 39 & Conquista & Garantia \\
\hline 40 e 42 & Conquista & Robusta \\
\hline 41 & Conquista & Conquista \\
\hline 43 a 46 & Romaria & Robusta \\
\hline 47 a 49 & Sacramento & Nobreza \\
\hline 50 a 51 & São João Batista do Glória & Conquista \\
\hline 52 & Iguatama & Conquista \\
\hline 53 & São João Del Rei & M-SOY 8400 \\
\hline 54 & São João Del Rei & Robusta \\
\hline 55 a 58 & Lagamar & Conquista \\
\hline 59 a 62 & Água Comprida & Nobreza \\
\hline 63 e 67 & Conceição das Alagoas & Conquista \\
\hline 68 e 69 & Rio Paranaíba & Garantia \\
\hline 70 & Rio Paranaíba & Robusta \\
\hline 71 & Rio Paranaíba & Conquista \\
\hline 72 a 74 & Presidente Olegário & Robusta \\
\hline 75 a 78 & Iraí de Minas & Robusta \\
\hline 79 & Uberaba & Conquista \\
\hline 80 e 84 & Uberaba & Sublime \\
\hline 81 e 82 & Uberaba & Confiança \\
\hline 83 & Uberaba & Garantia \\
\hline 85 & Uberaba & Robusta \\
\hline 86 & Paracatu & Conquista \\
\hline
\end{tabular}

Ciênc. agrotec., Lavras, v. 31, n. 3, p. 672-677, maio/jun., 2007 


\section{RESULTADOS E DISCUSSÃO}

$O$ resultado da eletroforese evidenciou que apenas as amostras amplificadas com o "primer" específico para $P$. pachyrhizi, agente etiológico da ferrugem "asiática", foram visualizadas nos géis. Utilizando o par de "primer" específico para a detecção da espécie $P$. pachyrhizi Ppm1/ Ppa1, ocorreu o aparecimento de bandas, cujo produto da reação foi uma banda equivalente a 141 pares de base (Figuras 1 e 2), e não houve aparecimento de bandas para a reação com o "primer" Ppm1/ Pme2 em 139 pares de base, para a $P$. meibomiae, exceto no controle (Figura 1).

Esses resultados demonstram que a espécie predominante nos principais campos de produção de soja do Estado de Minas Gerais, na safra 2003/04, foi de $P$. pachyrhizi. Essa espécie é considerada mais agressiva, o que explica os altos prejuízos verificados na última safra no estado.
De acordo com Deslandes (1979), a ferrugem "asiática" da soja foi detectada pela primeira vez em Lavras, MG infectando soja e outras leguminosas. O trabalho de Akamatsu et al. (2004) confirmou, através de técnicas moleculares que amostras coletadas no Estado de Minas Gerias, em 1979, eram de P. pachyrhizi, e apenas algumas amostras apresentavam as duas espécies. Os autores utilizaram para essa identificação amostras herborizadas entre 1979 e 1983 do Estado de Minas Gerais, sendo a extração do DNA genômico pelo método CTAB e a identificação molecular através de "primers" específicos para as duas espécies, a partir de regiões codificantes (18S, 5.8S e $28 \mathrm{~S}$ ) separadas por duas regiões transcritas, porém descartadas durante o processo (ITS1 e ITS2). Tal fato confirma os resultados deste trabalho.

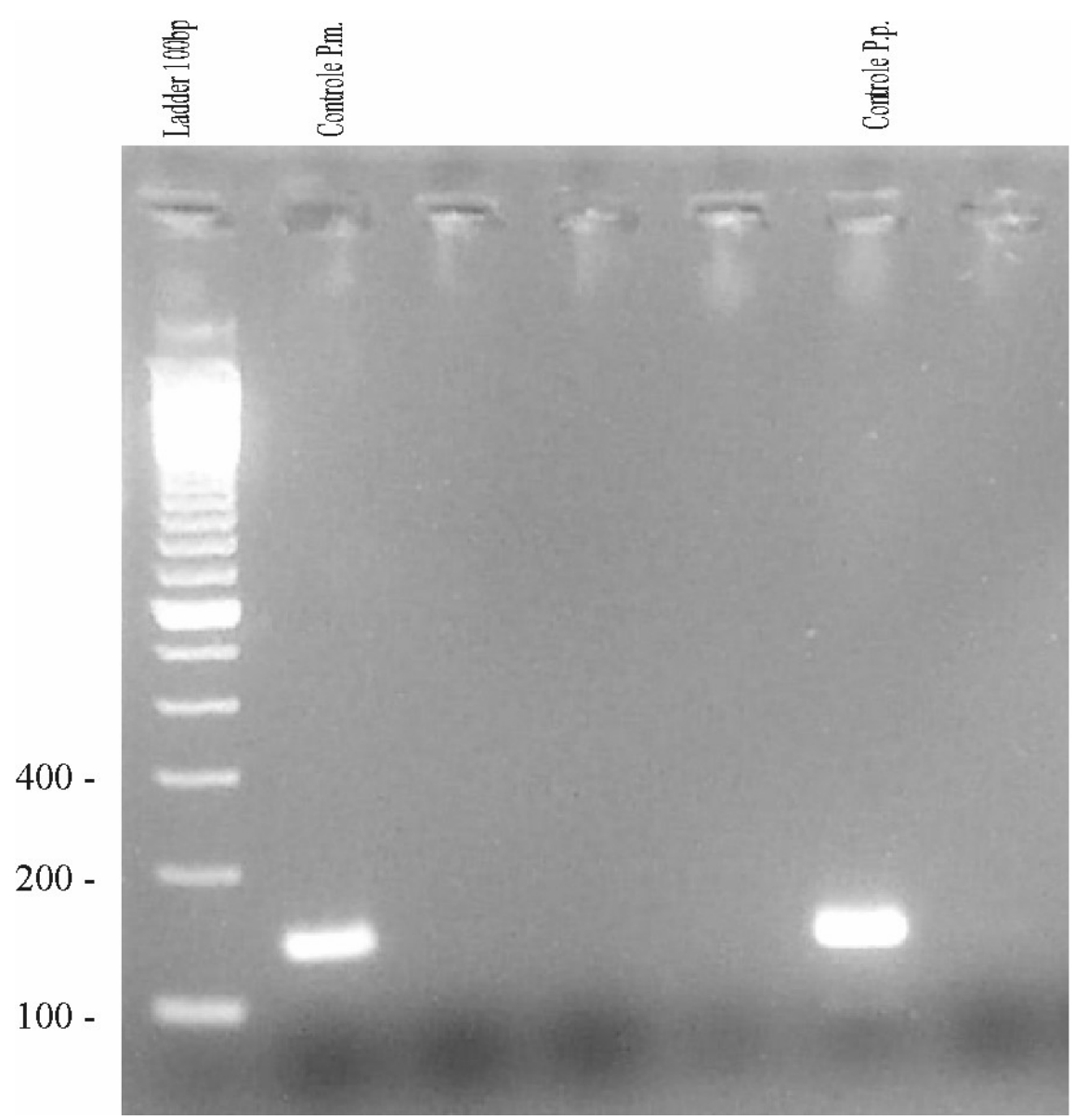

FIGURA 1 - Gel de agarose da reação de polimerase em cadeia (PCR) mostrando as bandas do controle P. m. (Primer Ppm1/Pme2 específico para Phakopsora meibomiae) em 139pb e do controle P.p. (Primer Ppm1/Ppa2 específico para Phakopsora pachyrhizi) em 141pb. 


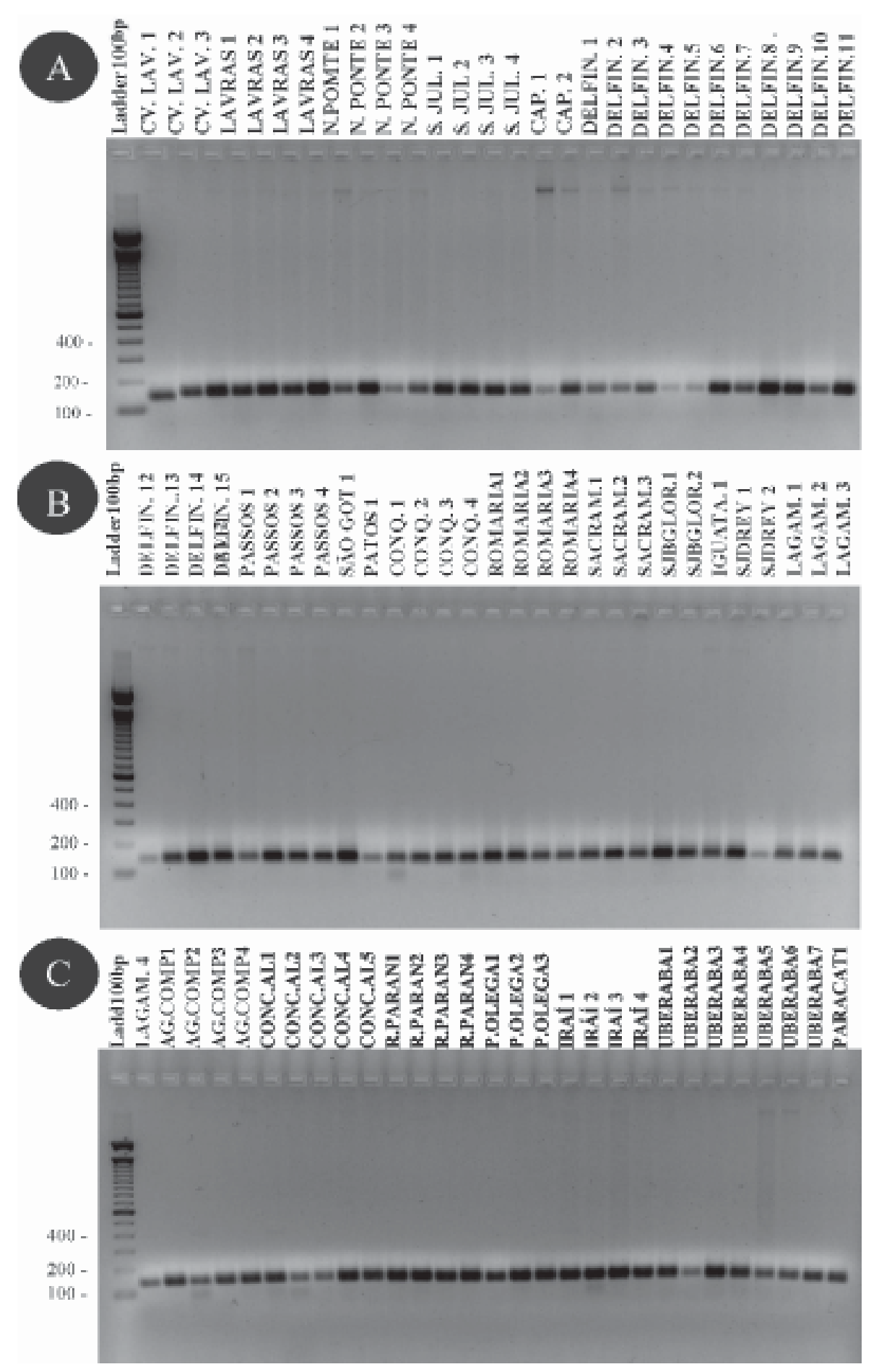

FIGURA 2 - Gel de agarose da reação de polimerase em cadeia (PCR). Primer Ppm1/Ppa2 específico para Phakopsora pachyrhizi, amostras 1-28 (A), amostras 29-58 (B) e amostras 59-86 (C).

Ciênc. agrotec., Lavras, v. 31, n. 3, p. 672-677, maio/jun., 2007 


\section{CONCLUSÕES}

Conclui-se que: $P$. pachyrhizi, agente etiológico da ferrugem "asiática" foi a espécie presente em todas as amostras, coletadas para este estudo, no Estado de Minas Gerais na safra 2003/04, o que indica que essa espécie se encontra amplamente distribuida no Estado, justificando os altos danos observados na cultura nesta safra.

\section{AGRADECIMENTOS}

Os autores agradacem ao Ministério da Agricultura, Pecuária e Abastecimento, Empresa Brasileira de Pesquisa Agropecuária (EMBRAPA),e a Empresa de Pesquisa Agropecuária de Minas Gerais (EPAMIG) deUberaba, na pessoa do Dr. Neylson Arantes, pelo apoio científico e logístico.

\section{REFERÊNCIAS BIBLIOGRÁFICAS}

AKAMATSU, M. A.; BARRETO, M.; AKAMATSU, R. Detecção e distinção de Phakopsora pachyrhizi e $P$. meibomiae em amostras do herbário uredinológico do Instituto Biológico. Fitopatologia Brasileira, Brasília, v. 29, p. 277-278, ago. 2004. Suplemento.

DESLANDES, J. A. Ferrugem da soja e de outras leguminosas causadas por Phakopsora pachyrhizi no Estado de Minas Gerais. Fitopatologia Brasileira, Brasília, v. 4, n. 2, p. 337-339, 1979.

FREDERICK, R. D.; SNYDER, C. L.; PETERSON, G. L.; BONDE, M. R. Polymerase chain reaction assays for the detection and discrimination of the soybean rust pathogens Phakopsora pachyrhizi and P. meibomiae. Phytopathology, Saint Paul, v. 92, n. 2, p. 217-227, 2002.
KAWUKI, R. S.; ADIPALA, E.; TUKAMUHABWA, P. Yield loss associated with soya bean rust (Phakopsora pachyrhizi Syd.) in Uganda. Journal of Phytopathology, Hamburg, v. 151, n. 1, p. 7-12, 2003.

MCDONALD, B. A. The populations genetics of fungi, tools and techniques. Phytopathology, Saint Paul, v. 87, n. 4, p. 448-453, 1997.

PIUGA, F. F.; ALMEIDA, A. M. R.; GODOY, C. V.; COSTAMILAN, L. M.; OLIVEIRA, A. C. B.; GUERZONI, R. A.; NUNES JÚNIOR, J.; PAIVA, W. M. Dupla infeção de Phakopsora pachyrhizi e P. meibomiae em lavouras de soja no Brasil. In: REUNIÃO PESQUISA DA SOJA DA REGIÃO CENTRAL DO BRASIL, 25., 2003, Uberaba. Resumos... Uberaba: [s.n.], 2003. p. 166-167.

RYTTER, J. L.; DOWLER, W. M.; BROMFIELD, K. R. Additional alternative hosts of Phakopsora pachyrhizi, causal agent of soybean rusts. Plant Disease, Saint Paul, v. 68, n. 11, p. $818-819,1984$.

SCHAAD, N. W.; FREDERICK, R. D. Real-time PCR and its application for rapid plant disease diagnostics. Canadian Journal of Plant Pathology, Ontário, v. 24, n. 3, p. 250-258, 2002.

YORINORI, J. T. Ferrugem asiática da soja: doença recente e preocupante. Correio Agrícola, São Paulo, v. 1, n. 1, p. 16-21, 2003.

YORINORI, J. T.; LAZZAROTTO, J. J. Situação da ferrugem asiática da soja no Brasil e na América do Sul. Londrina: Embrapa Soja, 2004. 27 p. (Documentos, 236). 